Revista de la Facultad de Geografia e Historia, núm. 1, 1987, págs. 261-274

\title{
Aportación al estudio de los conflictos sociales y políticos durante la II República en Andalucía: el caso de la sierra de Cádiz
}

\author{
Fernando Sigler Silvera
}

La historiografía de tipo local y comarcal, tratada con un adecuado nivel de rigurosidad científica y susceptible de servir como referencia válida para construcciones más generales, parece constituir una de las variadas necesidades que han de ir siendo cubiertas en la búsqueda de nuevas actitudes metodológicas y renovadas perspectivas para la compresión del pasado.

La comarca de la sierra de Cádiz, así, puede significar un marco geográfico coherente para abordar un análisis que responda a los presupuestos aludidos ${ }^{1}$, habiendo sido objeto ya de estudios específicos, tanto desde el campo de la Antropología ${ }^{2}$, como desde el de la propia Historia ${ }^{3}$.

\footnotetext{
${ }^{1}$ Esta comarcalización, desde un punto de vista geográfico, es estudiada en Juan Manuel SUAREZ JAPON, El habitat rural en la Sierra de Cádiz. Diputación provincial de Cádiz, Cádiz, 1981. Sin embargo, la tradicionalmente considerada como comarca natural, la Serranía de Ronda, integrada por zonas de las provincias de Cádiz y Málaga, es analizada en Francisco Rodriguez, La Serranía de Ronda, Málaga, 1977, y ha merecido diversos estudios históricos, como, a título de ejemplos, Manuel Acien Almansa, Ronda y su Serrania en tiempo de los Reyes Católicos. Universidad de Málaga, Málaga, 1977 (3 vols.); "Ronda capital de comarca, capital de provincia", por Ruiz CAstreño, en Revista Ronda y su Serranía, no especial, Ronda, 1982; "La Serranía de Ronda y la Guerra civil española", por Antonio NADAL, en Papeles de Historia, Revista de la Asociación Papeles de Historia, no 2, Ubrique (Cádiz), 1987 (en prensa), etc.

${ }^{2}$ J.P. PITT-RIVERs, Los hombres de la Sierra. Ensayo sociológico sobre un pueblo de Andalucía. Grijalbo, Barcelona, 1971; "Aproximación a un modelo de Etnografia religiosa en la Sierra de Cádiz", por Paloma Falqué Rey y Francisco Garcia Ferrero, en Papeles de Historia, $\mathrm{n}^{\circ}$ 2, Ubrique (en prensa). El antropólogo alemán, Thomas GABLER ha estudiado en concreto el pueblo de El Gastor, en una obra inédita en España. Para este último estudio véase "Sierra y libertad de un pueblo de la Serranía gaditana". por Thomas GABLER, en Papeles de Historia, $n^{\circ} 2$, L'brique (en prensa).

${ }^{3}$ Fernando Sigler Silvera, La ll República y los comienzos de la Guerra Civil en la Sierra de Cádiz: Ubrique (1931-1936) Memoria de Licenciatura, dirigida por JAVIER TUSELL. UNED, Madrid, 1986. En esta obra se hace referencia, al igual que en el presente artículo, a un
} 
La provincia de Cádiz en su conjunto ha recibido diversos acercamientos, en lo que a la Historia Contemporánea se refiere, en su mayor parte desde la óptica del movimiento obrero ${ }^{4}$.

También la Historia de localidades gaditanas individualizadas ha merecido algunos estudios, a veces en respuesta a la importancia que determinados acontecimientos locales revistieron para el desarrollo político del Estado, como los sucesos de Casas Viejas ${ }^{5}$.

conjunto de pueblos englobados en la más amplia denominación actual de Ruta de los Pueblos Blancos. Véase también el número monográfico " $V$ Centenario de la integración de la Serranía de Villaluenga en el señorio de la Casa de Arcos" (Actas I Seminario Historia de Ubrique), en Papeles de Historia, $n^{\circ}$ 1, Ubrique, 1986 (con textos de Manuel Gonzalez JIMENEZ, Manuel Acien Almansa, Pedro Parrilla Ortiz, Federico Devis Marquez y Luis Javier Guerrero MISA), para un ejemplo de estudio comarcal.

Volviendo a la época que nos ocupa, "Luchas politicas y conflictos sociales en al Sierra de Cádiz durante la Segunda República", por Diego Caro Cancela, en Papeles de Historia, no 2 , Ubrique (en prensa).

${ }^{4}$ Son ya clásicos los estudios como "Socialistas, anarcosindicalistas y anaquistas en la provincia de Cádiz en 1932-33", por Gérald BREY y Jacques MAURICE, en Manuel TUNON DE LARA (dir.), Sociedad, politica y cultura en la España de los siglos XIX-XX. III Coloquio de Pau. Edicusa, Madrid, 1973, págs. 229-254, y Temma KAPLAN, Origenes sociales del anarquismo en Andalucia. Capitalismo agrario y lucha de clases en la provincia de Cádiz, 1868-1903. Critic--Grijalbo, Barcelona, 1977. Esta última obra ha sido analizada críticamente en "Historia de Jerez y anarquismo", por Diego Caro Cancela, en Pliegos de Opinión, n 3-4, Revista de la Fundación Investigación y Debate. Jerez, 1986

Más recientes aportaciones las constituyen "Una aproximación cuantitativa a los conflictos obreros en la provincia de Cádiz durante la II República", por Diego CARO CANCELA, en Cádiz en su Historia. V Jornadas de Historia de Cádiz, Cádiz, 1986; Juan Antonio VILA MARTINEz, La rearticulación de la sociedad gaditana. Estudio tipológico del asociacionismo en Cádiz. Memoria de Licenciatura, dirigida por José ANDRES-GALLEGO, Universidad de Cádiz, Cádiz, 1986.; "Las Juntas de Reformas Sociales en la provincia de Cádiz (1900-1924)", por Félix Rubio Lopez De La Llave, en Papeles de Historia, $n^{\circ} 2$, Ubrique (en prensa).

Por otra parte, desde un punto de vista de Historia política debe destacarse Diego CARO CanCEla, La Segunda República en Cádiz: elecciones y partidos políticos, Diputación provincial, Cádiz, 1987; Enrique Del ARBol: "Problemática que plantea la multiplicidad de logias en Andalucía Occidental (provincia de Cádiz)", en La Masonería en la Historia de España, Zaragoza, 1985; José Luis MiLlan ChIVITE: "Cádiz en los tiempos contemporáneos", en J. RodRlGUez PIÑERo (coord.), Cádiz y su provincia, III, Gever, Sevilla, 1984; págs. 13-131. Debe hacerse mención también a las diversas aportaciones contenidas en la revista Gades, de la Universidad de Cádiz y la Diputación provincial, así como a las del Boletín Bibliográfico de Historia de la Fundación Municipal de Cultura de Cádiz.

${ }^{5}$ Gérard Brey y Jacques Maurice, Historia y leyenda de Casas Viejas. Zero, Madrid, 1976; "Campesinos de Medina Sidonia y Casas Viejas (1870-1933)", por Gérard BreY, en Tiempo de Historia, n²0, Madrid, julio 1976, págs. 44-55; Jerome R. MinTz, The Anarchists of Casas Viejas. Chicago, 1982. Sobre una localidad distinta, Fernando SIGLER SILVERA, Republicanismo y anarcosindicalismo en Ubrique (1931-1936). I Premio Concurso Anual de Monografías sobre temas de Ubrique. Area de Cultura del Ayuntamiento de Ubrique (en prensa). Por otra parte, la Diputación provircial tiene emprendida la edición de una desigual colección, la Historia de los pueblos de la provincia de Cádiz, de la que ya se han publicado 28 volúmenes. 
Esta línea parece merecer ser profundizada, para comprobar hasta qué punto son extensibles al conjunto los esquemas de los que Casas Viejas, por ejemplo, se ha constituido en representativo.

En este sentido, resulta interesante adentrarse en el debate acerca de la explicación del auge del movimiento anarcosindicalista en esta zona andaluza ${ }^{6}$, aunque, de todos modos, el predominio de las organizaciones libertarias en la Sierra de Cádiz, evidente durante el último cuarto del siglo XIX y primeras tres décadas del $x^{7}$, parece reducirse, al comienzo de la II República, a la subcomarca compuesta por Grazalema, Villaluenga y que, al tiempo que se producía un avance en la implantación ugetista. El líder anarquista de Morón de la Frontera, Antonio Rosado, ha relatado en sus memorias los esfuerzos para la constitución, en los primeros momentos del nuevo régimen, de una Federación Comarcal de Sindicatos de CNT que abarcase los pueblos de la Sierra de las provincias de Sevilla, Málaga y Cádiz, realizándose una primera reunión en Olvera (curiosamente, en los locales de la UGT) con asistencia, por parte de Cádiz, de los obreros de Alcalá del Valle, Torre Alháquime, Setenil, El Gastor, Zahara, Grazalema y Algodonales ${ }^{8}$.

Tradicionalmente se ha afirmado que en la base de esta orientación mayoritariamente anarquista del movimiento obrero de la Sierra estaban las condiciones de la estructura de la propiedad de la tierra. En este sentido, Jacques Maurice ha interpretado que a "mayor concentración de la propiedad rústica (corresponde un) mayor arraigo del anarquismo", si bien ha admitido la dificultad de generalizar este esquema ${ }^{9}$. El contexto latifun-

\footnotetext{
${ }^{6}$ Desde la explicación prácticamente genotípica contenida en Gérard BRENAN, El laberinto español. Antecedentes sociales y politicos de la Guerra Civil. Ruedo Ibérico, Barcelona, 1982, págs. 241 y ss., y en J.P. PITT-Rivers, Los hombres de la Sierra..., op. cit., págs, 259 y ss., hasta explicaciones más racionales que inciden en motivaciones como la propaganda en un momento oportuno, la eficacia en las luchas concretas y el desengaño ante la práctica política restauracionista, como se expone en Antonio M. CALERO: "El porqué del anarquismo andaluz. Aportaciones del caso de Granada", en Manuel TUÑon De LARA y Jean François Botrel, Movimiento obrero. Politica y literatura en la España contemporánea. Cuadernos para el Diálogo, Madrid, 1974, pág. 67; Jacques MAURICE: "Para una tipología del anarquismo andaluz", en Actas I Congreso de Historia de Andalucia. Andalucia Contemporánea (siglo XIX-XX), II, Caja de Ahorros y Monte de Piedad de Córdoba, 1979, pág. 387; prólogo de Antonio M. Bernal a las memorias de Antonio Rosado, op. cit. en nota 8.

${ }^{7}$ Cf. los estudios de Max Nettlau; Carlos Seco Serrano, alt. Actas de los Consejos y Comisión Federal de la Región Española (1870-74), II, Universidad de Barcelona, Barcelona, 1969; Temma Kaplan, Orígenes..., op. cit.; Antonio M. CALero, Movimientos sociales en Andalucia (1820-1936). Siglo XXI, Madrid, 1979.

${ }^{8}$ Gérard Brey "Socialistas...", op. cit.; Antonio Rosado, Tierra y liertad. Memorias de un campesino anarcosindicalista andaluz. Prólogo de Antonio M. Bernal. Crítica-Grijalbo, Barcelona, 1979, pág. 62

${ }^{9}$ Jacques MaURICE: "Para una tipología..." op. cit., 387
} 
dista de la comarca, a comienzos de los años 30, está fuera de dudas, alcanzando el promedio provincial el 58 por 100 de la tierra útil catastrada y el 60 por 100 del sector NE ${ }^{10}$. Sin embargo, Ubrique, donde la relación población activa/filiación anarquista fue ininterrumpidamente mayoritaria ${ }^{11}$, carecía de latifundios en su reducido término municipal, existiendo sólo, a la altura de 1931, 173 pequeños propietarios (que satisfacian menos de 50 pts. de contribución rústica al año) y 36 pequeños arrendatarios de explotaciones menores de 10 Has. ${ }^{12}$. Además, el trasvase de población activa del sector primario al secundario producido a lo largo de la República no produjo una disminución en el número de afiliados cenetistas. Ubrique pasó de contar en 1932 con 900 obreros del campo ${ }^{13}$ y unos 340 trabajadores del sector secundario ${ }^{14}$, a poseer ya en 1934 menos de 700 obreros agrícolas y pasar la cifra de población activa industrial en poco tiempo a acercarse a 450 . $Y$ aunque tradicionalmente el principal contingente anarquista residió en los jornaleros (además del Centro Obrero de Agricultores (COA) las otras sociedades anarquistas eran la Sociedad de Obreros Curtidores, con 57 afiliados en 1931 y 66 dos años después, y la Sociedad de Obreros Zapateros, con 36 afiliados al comenzar la República), la CNT local pasó de unos 1.100 afiliados en $1932{ }^{15}$ a 1.423 en $1936{ }^{16}$.

Ello no implica que la UGT no realizara también progresos en su implantación local. Así, la principal sociedad ugestista, la Sociedad de Obreros Petaqueros pasó de 195 miembros en 1932 a 253 en 1936 (ya con el nombre de Sociedad de Obreros Marroquineros "El Avance") ${ }^{17}$. Además , en agosto de 1933 se constituyó la Sociedad de Trabajadores de la Tierra (STT), que, sin embargo, sólo alcanzaría unos 40 afiliados (en mayo de 1936 pasó a denominarse Agrupación Local de Campesinos de Ubrique). Y en abril de 1936 líderes ugetistas propiciaban la constitución de la única sociedad obrera de exclusiva composición femenina, la Sociedad de

\footnotetext{
${ }^{10}$ Joseph Harrison, Historia económica de la España contemporánea, Vicens Vives, Barcelona, 1980, pág. 149; "Del momerito andaluz. Los campesinos sin campos", XI, por A. VALDES, en CNT no 35, 23-12-1932, pág. 3.

${ }^{11}$ Antonio M. Calero, Movimientos..., op. cit., pág. 27; Archivo Histórico Municipal de Ubrique (AHMU). Expedientes Impersonales (Exp. Imp.), A Asociaciones en general, Sociedades Obreras, 1931-36.

${ }^{12}$ AHMU, Policia Rural: Junta local de Reforma Agraria, 1931.

${ }^{13} \mathrm{Ibidem}$, Exp. Imp., A/Asociaciones... Del informe municipal al Gobierno civil, 16-1-1932. En esta cifra no se incluyen los hortelanos (30), albañiles y peones (58), a pesar de que todos se agrupaban dentro del COA (CNT).

${ }^{14} \mathrm{Ibidem}$. Se trataba de 195 petaqueros, 57 curtidores, 36 zapateros, 24 carpinteros y 16 panaderos.

${ }^{15}$ Ibidem.

16 "Luchas políticas y conflictos sociales...", por Diego CARO CANCELA, cit.

${ }_{17}$ AHMU, Exp. Imp.., Sociedades Obreras: Sociedad de Obreros Marroquineros "El Avance", Lista de afiliados, 1936.
} 
Obreras Sirvientas "Renacer" (si bien ésta no tuvo una adscripción ideológica explícita).

De todos modos, el superior aumento de militancia anarcosindicalista se ve reflejado en el cambio de denominación a que se vio obligado el Centro Obrero de Agricultores (COA), que en mayo de 1936 adoptó el nombre de Sindicato Unico de Oficios Varios, para acoger a trabajadores de los diversos gremios.

\section{DISTANCIAMIENTO Y DESBORDAMIENTO SOCIAL}

Este panorama, aparentemente diversificado $-y$ que a nivel teórico quedó plasmado en continuas acusaciones entre anarquistas y socialistas, como se desprende de la lectura de la prensa obrera-, quedaba en cierto modo desmentido en la práctica sindical local, en la que con frecuencia se observó una acción conjunta, de lo cual es claro exponente la participación de líderes de UGT ubriqueña en el movimiento insurreccional promovido por CNT en enero de 1933, desarrollado en Ubrique entre los días 11 y 17 , en medio de una huelga general, llegando los insurrectos al día 13 a cortar parte del fluido eléctrico, a intentar volar el puente de la carretera por donde habian de llegar las fuerzas de Asalto de Jerez pedidas por el alcalde, y a manifestarse ante el Ayuntamiento al grito de "iA las armas!" ${ }^{18}$. La detención, junto a líderes cenetistas, de miembros de UGT llegó a extrañar al gobernador civil ${ }^{19}$, si bien la medida fue ratificada por el alcalde y por el juez de instrucción de Grazalema ${ }^{20}$.

La actitud adoptada por el Ayuntamiento en este movimiento revolucionario fue considerada por todas las organizaciones obreras como manifestación de "abusos de autoridad y persecución encarnizada sobre elementos honrados de estas entidades", lievándose a cabo en señal de protesta una huelga general del 2 al 4 de marzo en petición de dimisión del Ayuntamiento en bloque, afirmándose en el oficio de huelga que "teniendo en cuenta (...) lo distanciado que este Ayuntamiento se halla del pueblo y por el poco aprecio que del trabajador hace, es preciso deje de regir los destinos del pueblo un Ayuntamiento que días tristes originó y que mayores disgustos puede ocasionar" ${ }^{21}$.

\footnotetext{
18 AHMU, O/Orden Público: "Expediente sobre los sucesos de enero de 1933".

19 Ibidem, H/Huelgas: "Expediente instruido con motivo de una huelga revolucionaria iniciada por obreros agricultores, (11-19)-1-1933, f 17, Gobernador civil a alcalde, 15-1-1933.

${ }^{20}$ Ibidem, Telegrama de Alcalde de Ubrique a Gobernador civil, 17-1-1933, $19 \mathrm{~h}$.

21 lbidem, "Expediente instruido con motivo de declaración de huelga de cuatro sociedades
} 
Esta toma de postura puede ser reveladora del paulatino distanciamiento del conjunto de la población con respecto a las instituciones republicanas. A nivel local, esta tendencia se hizo visible ya en mayo de 1932, cuando tanto la CNT como el Partido Republicano Radical-Socialista propusieron al Ayuntamiento (compuesto por cinco miembros de la coalición republicano-socialista, cinco independientes y cuatro monárquico-conservadores) la reconsideración del nombramiento de hijo adoptivo enfavor del diputado radical Santiago Rodríguez Piñero, el "benefactor" de los republicanos de la Sierra, acordado un año antes, por haber defendido en el Parlamento la restitución de la pena de muerte. Pero la reivindicación de la figura del diputado llevó a los gobernantes municipales a apoyar la propuesta de restitución de la pena capital, en un acuerdo votado por los cinco republicano-socialistas, de ellos tres radicales (entre los cuales, el alcalde), un miembro del PSOE (y de la UGT) y otro socialista independiente ${ }^{22}$. Este hecho, unido a los sucesos de enero de 1933 y a la posterior contestación social contra el Ayuntamiento, llevó a la agrupación Socialista de Ubrique. a criticar el "marasmo del Ayuntamiento burgués de Ubrique", declarando, "su incompatibilidad con tan nefasta labor, envolviendo en su censura a todos y a cada uno de los ediles, sin mirar su bandera política bajo la cual militan o dicen militar; sin fijarse tampoco si son burgueses u obreros, pues a todos alcanza la responsabilidad, particularmente a estos últimos" (en clara referencia a los dos concejales socialistas) ${ }^{23}$.

Oira manifestación de este distanciamiento, o, mejor, del desbordamiento ideológico de los límites político-sociales de la República por parte de las sociedades anarquistas lo constituyó el apoliticismo obrero y los altos índices de abstención electoral (en Ubrique votó en noviembre de 1933 sólo el 28,5 por 100 del cuerpo electoral; y en febrero de 1936 lo hizo el 60,6 por 100, con un índice 12 puntos inferior a la media nacional, si bien en niveles similares a los producidos en la provincia ${ }^{24}$. De todos modos, considerando el conjunto de la comarca cabe hablar de una clara discontinuidad, tanto en los índices de participación como en el sentido del voto. En noviembre de 1933 no superaron el 35 por 100 de participa-

obreras que piden la dimisión del Ayuntamiento, 26-2/5-3-1933, Sociedades Obreras a Alcalde, 25-2-1933.

22 A.H.M.U., Actas capitulares, no 521, sesión de 9-5-1932.

¿' El Pueblo (órgano de las Agrupaciones Socialistas en la provincia de Cádiz), nº 66, 12-41933, pág. 3.

${ }^{24}$ AHMU, Elecciones, Junta Local del Censo Electoral, 1933-36. Para los datos electorales de la zona, Diego Caro Cancela, La Segunda República..., op. cit., y Fernando Sigler Silvera, Republicanismo y anarcosindicalismo..., op. cit. Para las elecciones a nivel nacional, Javier TUSELL y otros, Las constituyentes de 1931: unas elecciones de transición. Centro de Investigaciones Sociológicas, Madrid, 1982; Idem, Las elecciones del Frente Popular en España. Cuadernos para el Diálogo. Madrid, 1971. 
ción El Gastor, Grazalema, Ubrique, Villaluenga, Zahara y Arcos; se situaron entre el 35 y el 50 por 100 Alcalá del Valle, Benaocaz, Olvera y Puerto Serrano; en otros pueblos la participación fue muy alta: 84,2 por 100 en El Bosque y 74,1 por 100 en Torre Alháquime. En cuanto al sentido del voto, en junio de 1931 situaron como cabeza a un radical Benaocaz, Algar, Algodonales, Alcalá, Zahara, Benamahoma, Torre Alháquime, Ubrique, Prado del Rey y Villamartín; por su parte, Arcos, Bornos, Villaluenga y Grazalema dieron mayor número de votos a un candidato socialista; Olvera a un radical-socialista; y El Bosque uniformemente a todos los candidatos gubernamentales.

En noviembre de 1933, la derecha triunfó en Algar, Arcos, Benaocaz, Bornos, Grazalema, Ubrique, Alcalá del Valle y Olvera; los radicales en Zahara, Algodonales y Villaluenga; y la izquierda en Prado del Rey, Puerto Serrano, Torre Alháquime, El Bosque, El Gastor y Villamartín. Y en febrero de 1936, el Frente Popular venció en Alcalá del Valle, Algar, Arcos, Bornos, Espera, Grazalema, El Gastor, Olvera, Prado del Rey, Ubrique, Villamartín y Torre Alháquime; y el Frente Antirrevolucionario en Benaocaz, Villaluenga, El Bosque, Algodonales y Zahara.

\section{CRISIS DEL REPUBLICANISMO}

Fue el republicanismo burgués el protagonista de la acción política durante estos años, junto a la creciente importancia de las Agrupaciones Socialistas. En Ubrique, en concreto, el Partido Republicano Radical, fundado en julio de 1931 (hasta entonces los radicales funcionaron dentro del Círculo Republicano-Socialista, constituido en 1910) ${ }^{25}$, fue el grupo político en el poder municipal prácticamente durante toda la República (salvo el período de septiembre de 1935 a febrero de 1936, en que actuó una gestora nombrada gubernativamente compuesta por miembros de la CEDA). Compuesto por pequeños industriales y propietarios, su presencia en el Ayuntamiento no supuso ruptura alguna con corporaciones anteriores. Los radicales representaron una continuidad institucional entre el régimen monárquico y el republicano: de los tres concejales, dos -el alcalde y el primer teniente de alcalde-, ambos por cierto masones desde 1910 y 1912 respectivamente ${ }^{26}$, eran concejales desde 1922 y 1917.

\footnotetext{
${ }^{25}$ Archivo del Gobierno Civil de Cádiz (AGCC), Registro de Asociaciones, I-II. El nombre adoptado oficialmente fue el de Círculo Instructivo Republicano Radical.

${ }^{26}$ Archivo Histórico Nacional, Sección Guerra Civil, Salamanca (AHN, S), Masonería, Leg. 167 B/29 y Leg. 322 B/29.
} 
La ruptura producida a nivel nacional en el partido de Lerroux tuvo su reflejo en Ubrique, donde los afiliados optaron unánimemente por el ala izquierda desgajada de aquél y liderada por Martínez Barrio, constituyéndose en mayo de 1934 el Partido Republicano Radical Autónomo ${ }^{27}$, que en octubre de 1935 se convertiría en Unión Republicana. Este partido llegó a contar en enero de 1936 con 90 afiliados en Ubrique, 82 en Villamartín, 70 en El Bosque, 50 en Arcos, Puerto Serrano, Algodonales, Olvera y El Gastor, 21 en Bornos y 17 en Grazalema, y en junio, 102 en Alcalá del Valle, 60 en Espera y 30 en Benaocaz ${ }^{28}$.

A la izquierda del radicalismo en Ubrique se constituyó en enero de 1932 el Partido Republicano Radical-Socialista ${ }^{29}$, compuesto por pequeños industriales y obreros marroquineros (muchos, afiliados a UGT). En octubre de 1932 pasó a denominarse Partido Republicano Radical-Socialista Independiente, constituyéndose en mayo de 1934 en Izquierda Republicana ${ }^{30}$. Los intentos de unificación de ambos partidos a nivel local no llegaron a fructificar.

En El Bosque, sin embargo, la crisis del republicanismo se vio envuelta en graves conflictos, que tuvieron su punto culminante el 1 de noviembre de 1932 al ser asesinado ante la puerta del Ayuntamiento el vicepresidente de la Sociedad Obrera Agrícola y de cuya autoría fue acusado un militante radical, siguiendo con continuas acusaciones entre radicales y radical-socialistas (representados estos últimos años por el secretario del Ayuntamiento, Santiago Pérez Fernández de Castro, candidato a diputado en 1933), y desembocando en la ruptura del comité local del Frente Popular, tras el estrepitoso fracaso electoral de esta candidatura, que no alcanzó el 3 por 100 de los votos emitidos, siendo expulsado del partido el vicepresidente de UR, quien junto a los presidentes de UGT y Agrupación Socialista y al vicepresidente de IR, criticó la formación de las listas de candidatos a concejales ${ }^{31}$.

Por último, en cuanto a la organización política de la izquierda obrera en Ubrique, en agosto de 1931 se constituyó la Agrupación Socialista, y

\footnotetext{
27 AHMU, Exp. Imp., A 173, Círculo Republicano Radical, 1934.

${ }^{28}$ AHN, S, Político-Social, Cádiz, carp 1-3. Para la evolución del PRR, Octavio Ruiz Manjon, El Partido Republicano radical, 1908-1936. Tebas, Madrid, 1976.

${ }^{29}$ AGCC, Registro de Asociaciones, I, ff $211 \mathrm{v}-222$.

${ }^{30}$ AHMU, Exp. Imp., A/172, Izquierda Republicana; AGCC, Registro de Asociaciones, I, $f$ 344. Para la evolución de este sector a nivel nacional, Juan AvILES FARRE. La izquierda burguesa en la /l República, Espasa-Calpe, Madrid, 1985.

31 Archivo Municipal de El Bosque, Secretaría: "Ayuntamiento y empleados", 1932-35; AHN, S, Político-Social, Cádiz, carp 2, ff 20-22; El Pueblo, n 55, 17-12-1932, pág. 3.
} 
sólo en abril de 1936 la Juventud Comunista ${ }^{32}$. El PC tuvo fuerza en Algodonales, donde el 12 de abril de 1931 obtuvo un concejal ${ }^{33}$.

\section{CONFLICTIVIDAD SOCIAL}

Las precarias condiciones de vida de la mayoría de la población, con unos elevados niveles de paro forzoso (el 23,3 por 100 de los obreros agrícolas de Ubrique en 1932, y el 33 por 100 en 1933), incidieron decisivamente en una actitud de protesta por el nivel de precios de los productos de primera necesidad y en solicitud de mejoras salariales a lo largo de toda la República. Incluso a la altura de mayo de 1936 el Sindicato Unico de Oficios Varios (CNT) de Ubrique comunicó al alcalde haber acordado "que los afiliados a este sindicato están dispuestos a no abonar desde esta fecha ni un sólo céntimo a los propietarios de casas de alquiler mientras éstos no rebajen el 50 por 100 a las casas del precio que actualmente tienen" ${ }^{34}$.

La discusión de las bases de trabajo, por su parte, es reveladora de la fuerza y el grado de aceptación de las propuestas obreras. Las del verano e invierno de 1931 fueron discutidas por Juntas Mixtas Arbitrales locales. En Ubrique fueron pactadas por CNT. Su propuesta para las bases de verano de 1931 de, por ejemplo, 5 pesetas y manutención para el trabajo en la era, se redujo finalmente a 4,25 pts. y manutención; sin embargo, la propuesta para el invierno de 1931-32, de 4,5 pts. para los yunteros fue aceptada ${ }^{35}$.

Como referencia, los precios establecidos en la localidad en abril de 1932, tras una negociación entre el alcalde y los comerciantes, forzada por una amenaza de huelga de todas las organizaciones obreras locales, eran de, por ejemplo, 2 pts. el litro de aceite, 0,9 pts. el kg. de arroz, 2,75 el de garbanzos, 0,6 el de patatas y 1,85 el de azúcar ${ }^{36}$.

\footnotetext{
32 AHMU, Exp. Imp., A1151, Agrupación Socialista; Ibidem, Juventud Comunista; AGCC, Registro..., I, ff $177 \mathrm{v}-178$ y II, ff $75 \vee-76$.

${ }_{33}$ Archivo Municipal de Algodonales, Elecciones, Junta Local del Censo Electoral, 1931. Según Diario de Cádiz, en Prado del Rey fueron elegidos seis comunistas (DC, 15-4-1931). Un día después el mismo periódico rectificaba, calificando a estos candidatos electos como antidinásticos.

${ }^{34}$ AHMU, Exp. Imp., Asociaciones en general.., Centro Obrero de Agricultores (COA, CNT) a Alcalde, 21-5-1936.

${ }_{35}^{35} \mathrm{Ibidem}$, Bases de Trabajo, Agricultores, 1931.

${ }^{36}$ Ibidem, Exp. Imp., Asociaciones... Del informe de la Alcaldia al Gobernador Civil, 6-4-1932.
} 
Pero a partir de las de invierno de 1932-33, las bases fueron discutidas por el Jurado Mixto de la Comarca de la Sierra, con la participación exclusiva, según Brey, de la UGT ${ }^{37}$, que estableció tres tipos de jornales para grupos de pueblos distintos: 5,25 pts. para Alcalá del Valle, Bornos, Espera, Olvera, Puerto Serrano, Setenil, Torre Alháquine y Villamartín; 5 pts. para Algar, Algodonales, El Bosque, Prado del Rey, Ubrique y Zahara; y 4,5 pts. para Benaocaz, El Gastor, Grazalema y Villaluenga. Estos jornales desfavorecieron, según el mismo autor, a los pueblos de predominio cenetista; sin embargo, de todos modos, para Ubrique el acuerdo supuso un aumento de 0,5 pts. Para las bases de invierno de 1934-35 y de 193536 , el jornal base descendió a $4,75,4,5$ y 4,25 pts. para cada grupo respectivamente.

Pero si la conflictividad social en la comarca de la Sierra fue muy aguda a lo largo de toda la República - lo que sería muy prolijo de detallar ahora ${ }^{38}$ - ello no fue óbice para la existencia de posturas, en el ámbito agricola, que, siendo partidarias de una transformación de las estructuras, no se revistieron de caracteres revolucionarios. Se trataba, en este sentido, de la actitud de una clase media campesina, cuyos representantes dirigieron en mayo de 1931 un manifiesto al Gobierno, en principio remitido por los labradores de Bornos y apoyada luego por los de Villamartín, Prado del Rey, Algar, Espera, Puerto Serrano, Algodonales y Olvera. Encuadrados en una línea de progresismo social y político, estos labradores veían peligrar su condición de clase media agrícola si no se acometía "la reforma tan deseada del problema agrario", pues "si no se acude urgentemente a ella (...) en materia agraria van a quedar solamente muy contados, o sean los latifundistas y semilatifundistas, ya que el resto irá sin duda de ninguna clase a engrosar las filas de los braceros" ${ }^{39}$, reivindicando como medidas protectoras de limitación de la renta catastral, el establecimiento de un precio mínimo remunerador para todos los cereales, la igualación de los catastros de arrendamientos rústicos a los urbanos y la creación de bancos agrícolas para préstamos a bajo interés.

Pero la reforma Agraria concitaría la oposición, distinta en sus argumentaciones obviamente, de propietarios y organizaciones anarquistas. En Ubrique, en concreto, se produjo un boicot a la formación de la Junta local de Reforma Agraria, con un 100 por 100 de abstención en la votación para la constitución de las comisiones respectivas de patronos y obreros ${ }^{40}$.

\footnotetext{
${ }^{37}$ Gérard BreY: "Socialistas..."op. cit., págs. 236 y ss.

${ }^{38}$ Fernando Siglek SilverA. La // República..., op. cit., págs. 115 y ss.

39 Diario de Cádiz, n² 28946, 21-5-1931, ediciones de mañana (pág. 1) y tarde (pág. 2).

${ }^{40}$ AHMU, Policia Rural, Junta Local de Reforma Agraria, 1931
} 
El COA (CNT), además, acordó en asamblea por unanimidad, en septiembre de 1931, "no desplazar de esta sociedad los compañeros que habian de formar parte de la Comisión de Policía Rural (que debía poner en práctica las medidas de laboreo forzoso) por estar dicho asunto en pugna con los principios de la organización a la cual está adherida esta Sociedad" ${ }^{41}$. Un año más tarde, la Federación de Trabajadores Agrícolas de la Comarca de Cádiz de CNT acusaba a "las autoridades representativas de la República, quizá por sugerencia del partido socialista y de los dirigentes de la UGT (...) (de) tratar de imponer su táctica colaboracionista a los núcleos obreros que defraudados vuelven su vista y encaminan sus pasos hacia nuevos horizontes emancipadores", quedando patente la opción rupturista (en una línea faísta) en la afirmación de que la política reformista pretendía "que el obrero de la ciudad y del campo (olvidara) su condición de explotado y (retrasase) su afán revolucionario" ${ }^{2}$. De todos modos, la CNT local, a pesar de no asistir a las sesiones de la Comisión de Policía Rural, realizó diversas propuestas para la aplicación del laboreo forzoso en una serie de fincas (noviembre de 1932, mayo de 1935 y febrero de 1936, esta última vez conjuntamente con UR, IR, Agrupación Socialista y UGT), que, en general fueron rechazadas ${ }^{43}$. En Ubrique, por tanto, no se produjeron asentamientos ni apenas se llevaron a cabo tareas de laboreo forzoso. El carácter anticolaboracionista de CNT puede explicar, pues, el continuo clima de agitación obrera. Sin embargo, aun en pueblos donde tuvieron lugar estos asentamientos continuó el clima de protestas obreras, como en el caso de Espera ${ }^{44}$, si bien éste se mantuvo, según Malefakis, en un grado moderado. Precisamente, el fracaso de la experiencia de cultivo colectivo de Espera proporcionó a la candidatura de derecha en la campaña electoral de 1936 un argumento de invalidación de las propuestas del Frente Popular ${ }^{45}$.

La agitación, por supuesto, no se limitó a los pueblos de predominio cenetista. En Setenil, por ejemplo, días antes de la insurrección anarquista de diciembre de 1933 (que en Ubrique incidió a través de una huelga general), los obreros agrícolas protagonizaron un grave conflicto, al quedar "suspendidas las faenas (de) recolección (de) aceituna por coacciones (de) obreros parados, los cuales apalearon a los que se hallaban trabajando",

A.H.M.U.,

${ }^{42}$ CNT, n० 14, †7-11-1932, pág. 2.

${ }^{43}$ AHMU, Exp. Imp., P/38: "Paro forzoso: Expediente con motivo de petición de varias sociedades políticas y obreras para gestionar trabajo para combatir el paro forzoso", 27-21936.

${ }^{44}$ Edward Malefakis, Reforma Agraria y revolución campesina. Ariel, Barcelona, $5^{\mathrm{a}}$ ed., 1982, p.364.

${ }^{45}$ El Guadalete, no 26246, 25-1-1936, pág. 1. 
interviniendo la Guardia Civil para su sofocación ${ }^{46}$. En consecuencia, nueve militantes socialistas fueron detenidos y encarcelados. $Y$ tras la huelga de junio de 1934, otros 21 fueron asimismo detenidos ${ }^{47}$.

En Prado del Rey, por su parte, el movimiento revolucionario de octubre de 1934 tuvo una importante incidencia, al hacerse los revolucionarios con el control del pueblo en la noche del día 7 al $8^{48}$.

Pero, fue la explosión anticlerical la vía de una manisfestación masiva de violencia revolucionaria, y que si en Ubrique tuvo un encauzamiento institucional (el Ayuntamiento de mayoría republicano-socialista rompió las relaciones con el párroco en enero de 1934 y prohibió los entierros católicos ese mismo año; el gobierno municipal del Frente Popular [UR, IR, PSOE] decidió solicitar al Gobierno la municipalización de las iglesias para convertirlas en escuelas, centros obreros, oficinas municipales y lugares de esparcimiento, limitó el toque de campanas y expulsó a la comunidad de frailes capuchinos), éste se vio desbordado por el radicalismo popular, que tuvo su cénit en los incendios de iglesias de abril de $1936{ }^{49}$.

He aquí, pues algunas consideraciones acerca de la conflicitividad social y política en una comarca en la que aquélla se caracteriza por la no uniformidad, sobre todo en lo que respecta a la implantación sindical y al comportamiento electoral. Ubrique, sin embargo, ha sido tomado como ejemplo prototípico de núcleo rural de predominio anarcosindicalista, en el intento de servir de aportación para estudios de más amplia proyección espacial.

\footnotetext{
${ }^{46}$ Archivo General de la Administración, Alcalá de Henares, Gobernación, Leg. $798\left(1^{\mathrm{a}}\right.$ parte), caja 2. 412, Telegrama del gobernador civil de Cádiz a Ministro de la Gobernación, $n^{\circ}$ 181, 6-12-1933, $13 \mathrm{~h}$ (copia).

${ }^{47}$ AHN, S, Político-Social, Cádiz, carp 4/91.

${ }^{48}$ Archivo Municipal de Prado del Rey, Actas Capitulares, 1934.

${ }^{49}$ Fernando Sigler SilverA, La $/ /$ República..., op. cit., págs. 110 y ss.
} 